\title{
CD36 modulates migration of mouse and human macrophages in response to oxidized LDL and may contribute to macrophage trapping in the arterial intima
}

\author{
Young Mi Park, ${ }^{1,2}$ Maria Febbraio, ${ }^{1}$ and Roy L. Silverstein ${ }^{1}$ \\ 1Department of Cell Biology, Lerner Research Institute, Cleveland Clinic Foundation, Cleveland, Ohio, USA. 2PhD Program in Cell Biology,
} Case Western Reserve University, Cleveland, Ohio, USA.

\begin{abstract}
The trapping of lipid-laden macrophages in the arterial intima is a critical but reversible step in atherogenesis. However, the mechanism by which this occurs is not clearly defined. Here, we tested in mice the hypothesis that CD36, a class B scavenger receptor expressed on macrophages, has a role in this process. Using both in vivo and in vitro migration assays, we found that oxidized LDL (oxLDL), but not native LDL, inhibited migration of WT mouse macrophages but not CD36-deficient cells. We further observed a crucial role for CD36 in modulating the in vitro migratory response of human peripheral blood monocyte-derived macrophages to oxLDL. oxLDL also induced rapid spreading and actin polymerization in CD36-sufficient but not CD36-deficient mouse macrophages in vitro. The underlying mechanism was dependent on oxLDL-mediated CD36 signaling, which resulted in sustained activation of focal adhesion kinase (FAK) and inactivation of Src homology 2containing phosphotyrosine phosphatase (SHP-2). The latter was due to NADPH oxidase-mediated ROS generation, resulting in oxidative inactivation of critical cysteine residues in the SHP-2-active site. Macrophage migration in the presence of oxLDL was restored by both antioxidants and NADPH oxidase inhibitors, which restored the dynamic activation of FAK. We conclude therefore that CD36 signaling in response to oxLDL alters cytoskeletal dynamics to enhance macrophage spreading, inhibiting migration. This may induce trapping of macrophages in the arterial intima and promote atherosclerosis.
\end{abstract}

\section{Introduction}

Cardiovascular disease is currently the leading cause of death in many developed countries, and atherosclerosis is the most important underlying pathology (1). Atherosclerosis is a disease characterized by accumulation of lipids and an inflammatory response in the arterial intima, resulting in the formation of plaque that can lead to arterial narrowing and that is susceptible to rupture with acute thrombotic occlusion $(2,3)$. In the initial stage of atherogenic inflammation, monocyte-derived macrophages perform a critical role by internalizing oxidized LDL (oxLDL) through scavenger receptors $(4,5)$. While macrophages normally migrate after engulfing pathogens, these lipid-laden macrophages, known as foam cells, do not leave the lesion after clearing the lipids (6). Thus, their normal biological role is perturbed. Moreover, macrophages trapped in the arterial intima provoke an inflammatory response at the local site (7-9). Previous studies of atherosclerotic plaque regression revealed that the regressed lesion was characterized by disappearance of foam cells $(10,11)$ caused by their emigration from plaque into regional lymph nodes (11). Understanding mechanisms that regulate macrophage trapping in lesions and

Conflict of interest: The authors have declared that no conflict of interest exists. Nonstandard abbreviations used: DCF, $2^{\prime}, 7^{\prime}$-dichlorodihydrofluorescein; DPI, diphenyleneiodonium sulfate; FAK, focal adhesion kinase; $\mathrm{MPO}$, myeloperoxidase; NAC, $N$-acetyl-cysteine; $\mathrm{NO}_{2} \mathrm{LDL}$, oxLDL generated by $\mathrm{MPO}$ and nitrite; $\mathrm{NO}_{2}{ }^{-} \mathrm{LDL}$ nonoxidized LDL preparation that was exposed to all components of the MPO system except the oxidant; oxLDL, oxidized LDL; SHP-2, Src homology 2 domain-containing phosphotyrosine phosphatase; TSP-1, thrombospondin-1.

Citation for this article: J. Clin. Invest. 119:136-145 (2009). doi:10.1172/JCI35535. foam cell emigration from lesions could lead to development of novel strategies for the treatment of atherosclerosis.

CD36, a member of scavenger receptor B family, is a transmembrane glycoprotein receptor that is expressed in a variety of cells, including monocytes and macrophages. Macrophage CD36 has been implicated in atherogenesis by mediating uptake of oxLDL and foam cell formation (12), and Cd36-null mice on the proatherogenic Apoe-null background showed significantly less atherosclerotic lesion formation (12-15) than Apoe-null mice. Recent studies have also revealed that macrophage CD36 functions as a signaling molecule, transmitting signals via specific Src and MAP kinases, including Lyn and JNK1 and JNK2 upon binding to ligands, including oxLDL $(16,17)$. These signals are required for oxLDL internalization and foam cell formation (16).

In the current study, we set out to test the hypothesis that CD36 signaling in response to oxLDL may contribute to cytoskeletal rearrangements and thus macrophage spreading and migration. We report using both in vitro and in vivo assays that oxLDL induced CD36-dependent inhibition of migration. Mechanistically, this inhibition was associated with generation of ROS, enhancement of focal adhesion kinase (FAK) phosphorylation and actin polymerization, and inhibition of Src homology 2 domain-containing phosphotyrosine phosphatase (SHP-2). These studies thus reveal a potential mechanism for macrophage trapping in atherosclerotic lesions.

\section{Results}

oxLDL inhibits macrophage migration in vivo in a CD36-dependent manner. To evaluate the effect of oxLDL on macrophage migration 
A
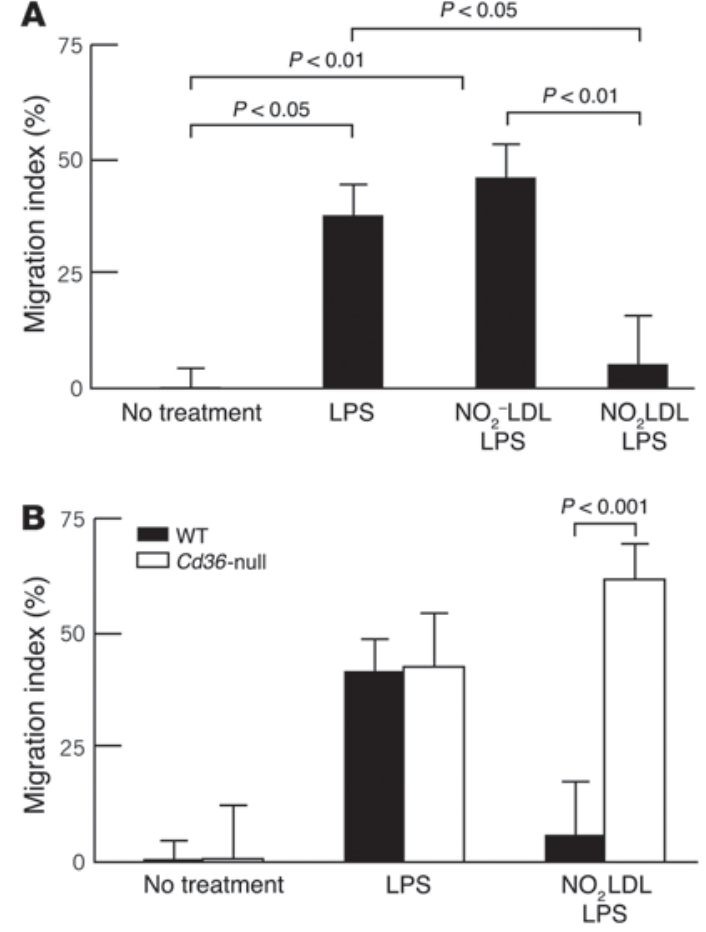

C
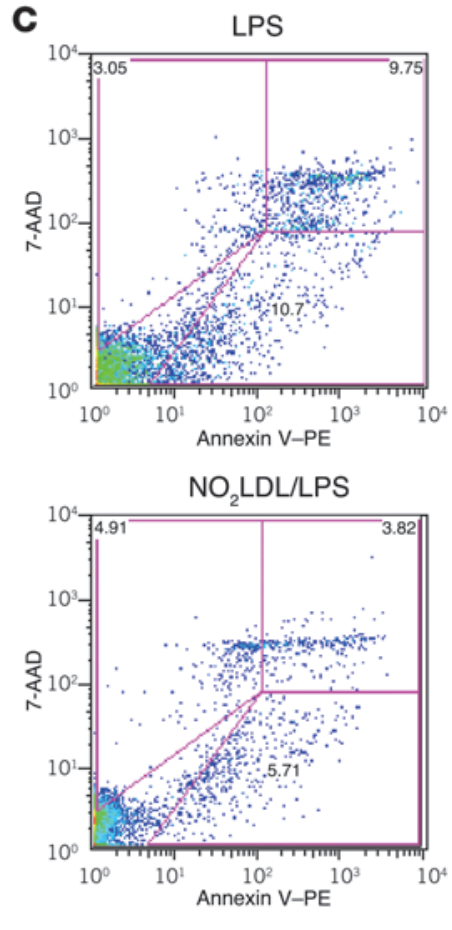

\section{Figure 1}

Macrophage migration in vivo is inhibited by $\mathrm{NO}_{2} \mathrm{LDL}$ in a CD36-dependent manner. (A) Thioglycollate-elicited peritoneal macrophages were isolated by lavage and counted 4 hours after mice were injected intraperitoneally with LPS. In some cases, mice were pretreated with $\mathrm{NO}_{2} \mathrm{LDL}$ or control LDL $\left(\mathrm{NO}_{2}-\mathrm{LDL} ; 50 \mu \mathrm{g}\right)$ prior to LPS injection. Data are plotted as the migration index, defined as [1 - (peritoneal macrophage count from each animal/average number of peritoneal macrophages of the thioglycollate-only control group mice) $] \times 100(\%) \cdot n=10-15$ per group; significance was determined by ANOVA and Bonferroni's multiple comparison test. (B) Migration was evaluated as in A, but in WT and Cd36-null mice. (C) Peritoneal macrophages from LPS- (upper panel) or LPS- and $\mathrm{NO}_{2}$ LDL-injected (lower panel) WT mice were stained with annexin $\mathrm{V}$ and 7-amino-actinomycin D (7-AAD) and subjected to analysis by flow cytometry. in vivo, we measured LPS-induced efflux of murine macrophages from the peritoneal cavity using the method developed by Cao et al. (18). In this assay, the number of macrophages remaining in the peritoneal cavity after an intraperitoneal injection of LPS is determined and compared with that of macrophages remaining after PBS injection. We used a form of oxLDL generated by myeloperoxidase (MPO) and nitrite that we term $\mathrm{NO}_{2} \mathrm{LDL}$ in these studies. This is a specific high-affinity ligand for CD36 with little capacity to bind scavenger receptor A (19). We first confirmed the observation by Cao et al. that LPS induced efflux of macrophages from the peritoneal cavity; approximately $40 \%$ of macrophages migrated from the peritoneal cavity 4 hours after LPS injection. No efflux was observed, however, when mice were injected with $\mathrm{NO}_{2}$ LDL prior to LPS (Figure 1A). A control, a nonoxidized LDL preparation that was exposed to all components of the MPO system except the oxidant (termed $\mathrm{NO}_{2}-\mathrm{LDL}$ ) had no such inhibitory effect on emigration. Intraperitoneal injection of LPS in Cd36-null mice induced macrophage efflux to similar degree as in WT mice, but unlike in the WT mice, $\mathrm{NO}_{2} \mathrm{LDL}$ did not have an inhibitory effect (Figure 1B). These studies suggest that peritoneal macrophage trapping by $\mathrm{NO}_{2} \mathrm{LDL}$ is dependent on CD36.

To exclude the possibility that the inhibitory effect of $\mathrm{NO}_{2} \mathrm{LDL}$ was due to induction of macrophage apoptosis, we analyzed the peritoneal cells by flow cytometry. As shown in Figure 1C, 10.7\% of the macrophages taken from mice after intraperitoneal injection of LPS stained positively with annexin V, indicating early apoptosis, and $9.75 \%$ stained with both annexin $V$ and 7 -amino-actinomycin $\mathrm{D}$ (7-AAD), indicating late apoptosis. Treatment with $\mathrm{NO}_{2} \mathrm{LDL}$ prior to LPS did not influence the degree of apoptosis; $5.71 \%$ of the cells showed evidence of early apoptosis and 3.82\% late apoptosis. oxLDL inhibits macrophage migration in vitro in a CD36-dependent manner. Having shown CD36-mediated inhibition of emigration by oxLDL in vivo, we next showed that $\mathrm{NO}_{2} \mathrm{LDL}$ inhibited migration of macrophages in vitro using a modified Boyden chamber.
We quantified migration by staining the nuclei of the migratory cells on the lower side of insert membrane. Figure $2 \mathrm{~A}$ shows that $\mathrm{NO}_{2} \mathrm{LDL}$ inhibited both random and monocyte chemotactic protein-1-directed (MCP-1-directed) macrophage migration; without MCP- $1, \mathrm{NO}_{2}$ LDL inhibited migration by $98 \%$ and with MCP- 1 , by $87 \%$. We examined the effect of various other lipoproteins including $\mathrm{HDL}, \mathrm{NO}_{2}{ }^{-} \mathrm{LDL}$, acetylated LDL (Ac-LDL), and copper-oxidized $\mathrm{LDL}\left(\mathrm{Cu}^{2+} \mathrm{OxLDL}\right) . \mathrm{Cu}^{2+}$ oxLDL inhibited macrophage migration to the same degree as $\mathrm{NO}_{2} \mathrm{LDL}$ (Figure $2 \mathrm{~B}$ ), while $\mathrm{NO}_{2}-\mathrm{LDL}$, Ac-LDL, and HDL had no effect. Using peritoneal macrophages from WT and Cd36-null mice, we showed that $\mathrm{NO}_{2} \mathrm{LDL}$ inhibition of macrophage migration was CD36 dependent (Figure 2C). Cd36-null macrophages migrated to the same extent as WT under basal conditions, but in the presence of $\mathrm{NO}_{2} \mathrm{LDL}$, WT cells were inhibited by greater than $80 \%$, whereas Cd36-null macrophage migration was inhibited by less than $40 \%$. We also performed migration assays with murine macrophages pretreated with a monoclonal antibody against CD36 and found that the level of migration in response to $\mathrm{NO}_{2} \mathrm{LDL}$ was similar to that observed in Cd36-null cells (data not shown), further supporting the hypothesis that oxLDL-induced inhibition of macrophage migration in vitro is partially dependent on CD36.

Inhibition of macrophage migration by oxLDL was also observed with human peripheral blood monocyte-derived macrophages. $\mathrm{NO}_{2} \mathrm{LDL}$ inhibited migration in the Boyden chamber by approximately $75 \%$ (Figure 2D), whereas $\mathrm{NO}_{2}-\mathrm{LDL}$ had no significant effect (data not shown). We observed the same degree of inhibition of migration by $\mathrm{NO}_{2}$ LDL using THP-1 cells, a human monocytic cell line, that were differentiated to macrophage-like cells by incubation with PMA (data not shown). The migration-inhibitory effect of $\mathrm{NO}_{2} \mathrm{LDL}$ was prevented by pretreatment of human monocyte-derived macrophages with a monoclonal antibody against CD36 but not an isotype-matched control IgG (Figure 2D).

We also examined the effect of thrombospondin-1 (TSP-1) on macrophage migration. TSP- 1 is a CD36 ligand that mediates an antian- 
A Without $\mathrm{NO}_{2} \mathrm{LDL}$
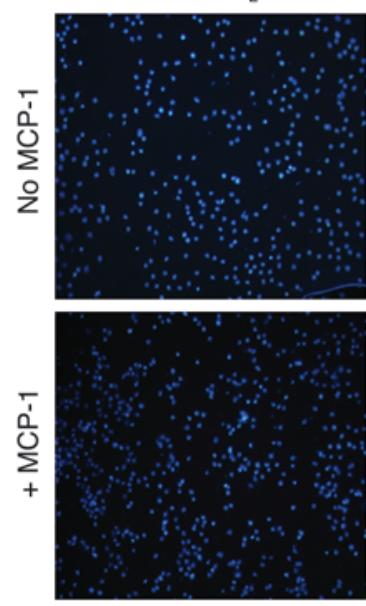

With $\mathrm{NO}_{2} \mathrm{LDL}$
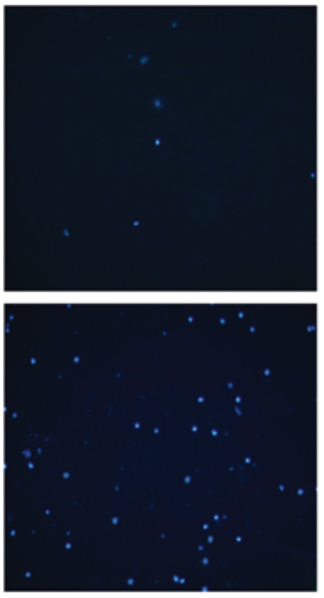

B

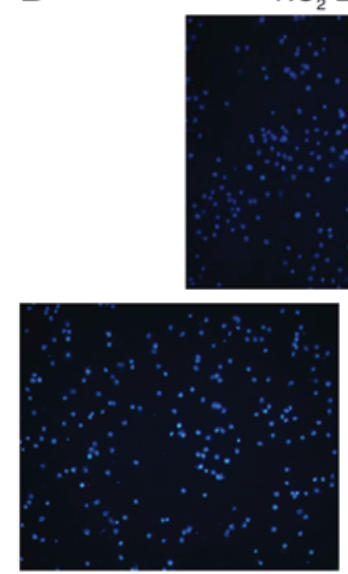

Ac-LDL
$\mathrm{NO}_{2}-\mathrm{LDL}$
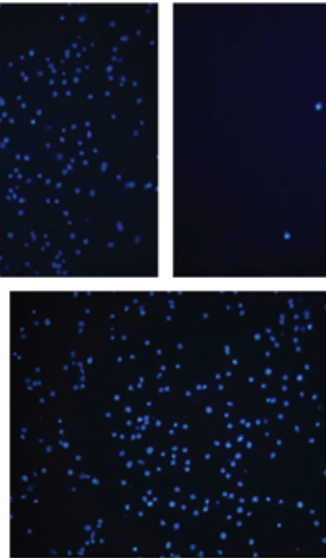

HDL
$\mathrm{Cu}^{2+} \mathrm{OxLDL}$
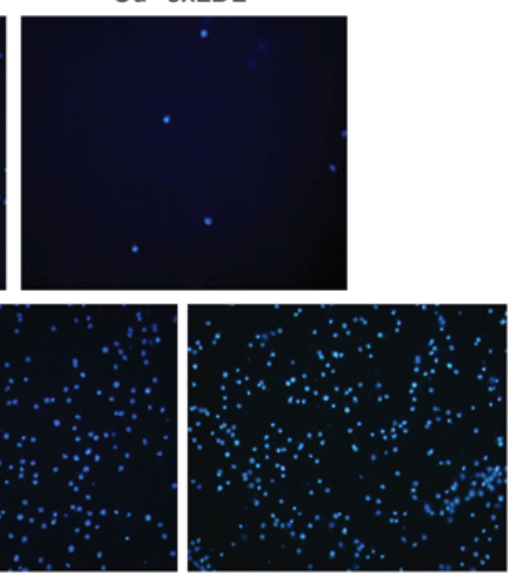

TSP-1

MCP-1 (10 ng/ml)
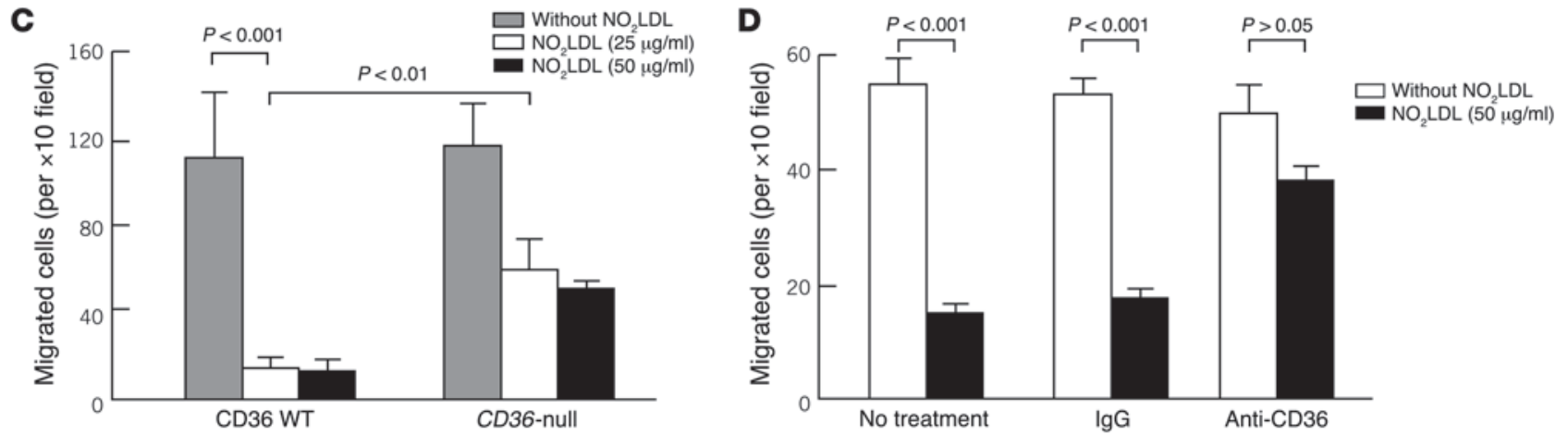

\section{Figure 2}

Murine and human macrophage migration in vitro is inhibited by $\mathrm{NO}_{2} \mathrm{LDL}$ in a CD36-dependent manner. (A) Murine peritoneal macrophages were added to the upper chamber of the Transwell with or without $\mathrm{NO}_{2} \mathrm{LDL}(50 \mu \mathrm{g} / \mathrm{ml})$ and allowed to migrate through the porous membrane into the lower chamber containing medium alone or medium with monocyte chemotactic protein-1 (MCP-1). Migrated cells on the lower side of the membrane were stained with DAPI and counted under a fluorescence microscope using a $\times 10$ objective. (B) $\mathrm{NO}_{2}{ }^{-} \mathrm{LDL}, \mathrm{Cu}^{2+} \mathrm{OxLDL}, \mathrm{Ac}-\mathrm{LDL}$, $\mathrm{HDL}(50 \mu \mathrm{g} / \mathrm{ml}$ each), or TSP-1 (20 nM) was added to the migration chamber and migration quantified as above. (C) Peritoneal macrophages from WT and Cd36-null mice were exposed to 0,25 , and $50 \mu \mathrm{g} / \mathrm{ml} \mathrm{NO} \mathrm{NDL}_{2}$ and migrated cells quantified as in A. (D) Human peripheral blood monocyte-derived macrophages were treated with isotype-matched control lgG or anti-CD36 monoclonal antibody (5 $\mathrm{gg} / \mathrm{ml})$ and were added to the migration chamber with or without $\mathrm{NO}_{2} \mathrm{LDL}(50 \mu \mathrm{g} / \mathrm{ml})$. Macrophage migration was quantified as in $\mathbf{A}$.

giogenic function in microvascular endothelial cells (20,21). TSP-1 did not inhibit macrophage migration in the Boyden chamber (Figure $2 \mathrm{~B}$ ), suggesting that the migration-inhibitory effect of $\mathrm{NO}_{2} \mathrm{LDL}$ may be driven by the oxidized lipid moiety or that additional TSPmediated signals from other receptors may negate the CD36 effect.

oxLDL induces rapid CD36-dependent macrophage spreading and actin polymerization. Cell migration is a complex process that involves cellular spreading, disruption of existing focal contacts, and formation of new focal contacts (22). We thus examined the effect of oxLDL on macrophage spreading as the first step of migration. $\mathrm{NO}_{2} \mathrm{LDL}$ induced rapid spreading of WT macrophages on serumcoated glass coverslips, while $\mathrm{NO}_{2}{ }^{-} \mathrm{LDL}$ did not (Figure 3A). After 5 minutes exposure to $\mathrm{NO}_{2} \mathrm{LDL}$, there were 3 times more spread WT cells than spread Cd36-null cells relative to total cells (Figure $3 \mathrm{~B}$ ). The mean cellular area of WT cells was rapidly increased by $\mathrm{NO}_{2} \mathrm{LDL}$, while Cd36-null cells showed a pronounced blunting and delay in response (Figure 3C). Similar results were observed using $\mathrm{Cu}^{2+}$ oxLDL (data not shown).
Since cell spreading requires actin polymerization to form lamellipodia (23), we examined the effect of $\mathrm{NO}_{2} \mathrm{LDL}$ on the actin cytoskeleton. Macrophages from WT and Cd36-null mice were treated with $\mathrm{NO}_{2} \mathrm{LDL}$ and then stained with fluorescein-conjugated phalloidin to detect polymerized actin. Flow cytometric analysis showed that the amount of polymerized actin was increased by $\mathrm{NO}_{2} \mathrm{LDL}$ in WT but not Cd36-null cells (Figure 3D).

oxLDL induces CD36-dependent phosphorylation of FAK. Since the signaling pathway required for actin polymerization includes activation of FAK (24), we evaluated the state of FAK phosphorylation after macrophage exposure to oxLDL. Western blot analyses revealed that $\mathrm{NO}_{2} \mathrm{LDL}$ increased Tyr576/577 phosphorylation of FAK in WT but not in Cd36-null cells (Figure 4A). Phosphorylation could have resulted from either direct CD36 signaling or from CD36-mediated uptake of biologically active oxidized lipids. We thus incubated peritoneal macrophages from WT mice with $\mathrm{NO}_{2} \mathrm{LDL}$ at $37^{\circ} \mathrm{C}$, a temperature at which $\mathrm{NO}_{2} \mathrm{LDL}$ uptake proceeds, or at $4^{\circ} \mathrm{C}$, at which $\mathrm{NO}_{2} \mathrm{LDL}$ binds but is not internalized 
A
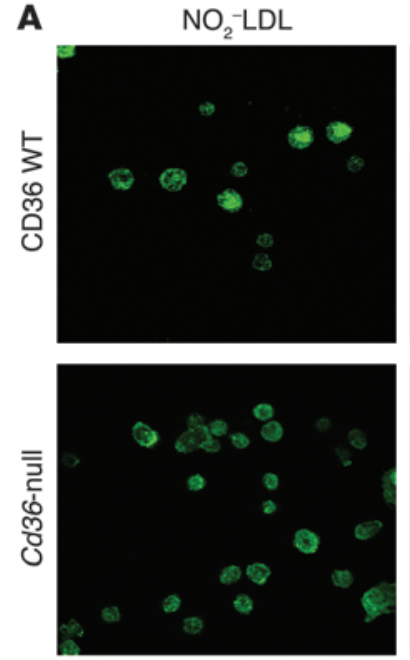

C

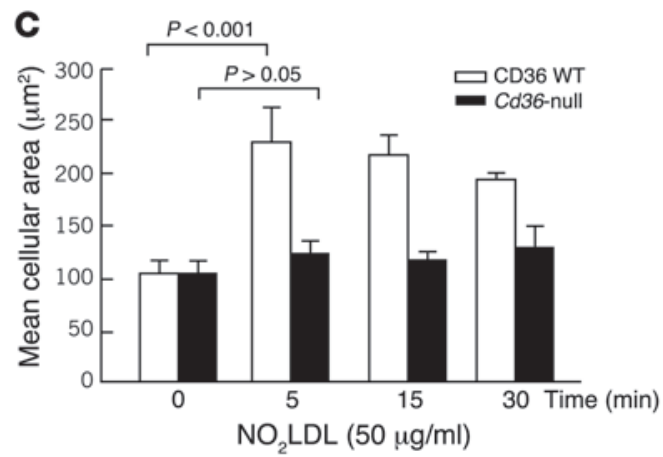

B
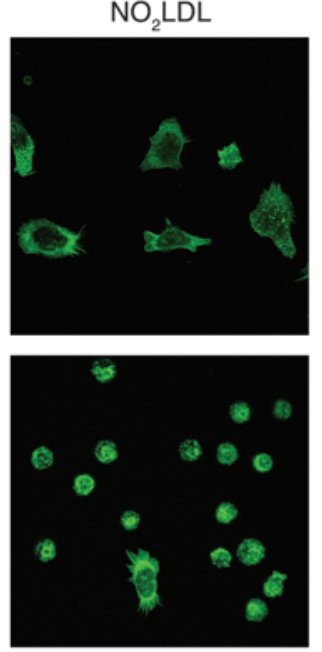

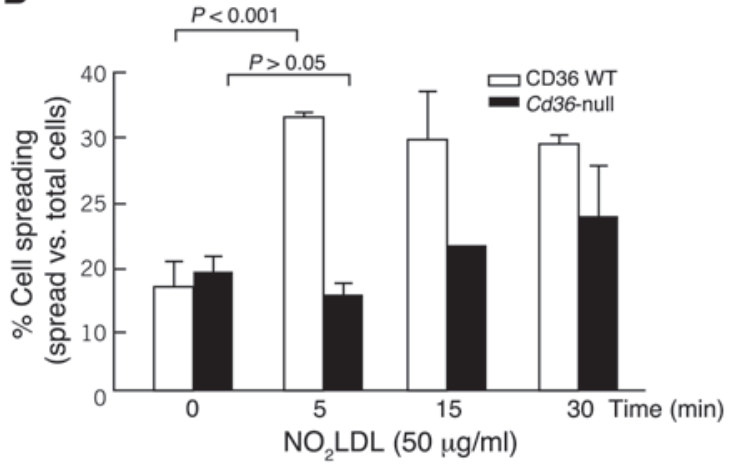

D
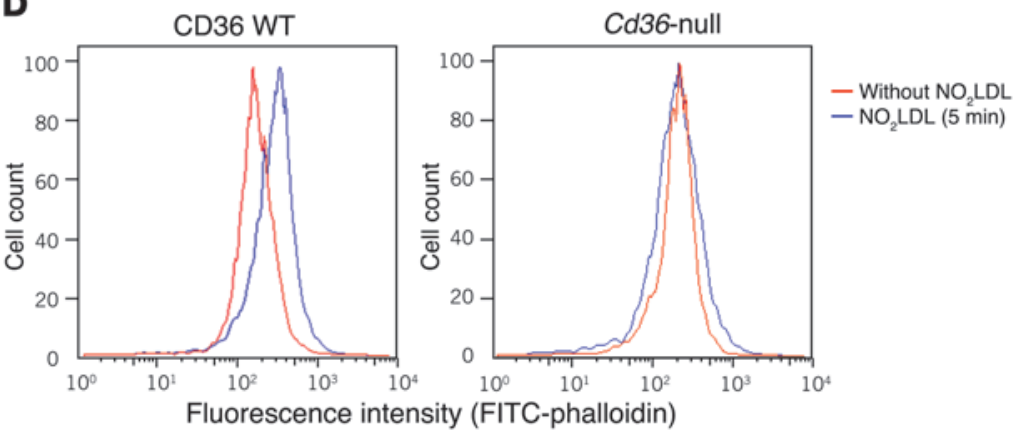

Figure 3

$\mathrm{NO}_{2} \mathrm{LDL}$ induces rapid macrophage spreading and actin polymerization in a CD36-dependent manner. (A) Macrophages from WT and Cd36-null mice were plated on serum-coated glass coverslips, incubated with $\mathrm{NO}_{2}-\mathrm{LDL}$ or $\mathrm{NO}_{2} \mathrm{LDL}(50 \mu \mathrm{g} / \mathrm{ml})$ at $37^{\circ} \mathrm{C}$, and then photographed after 5 minutes (original magnification, $\times 94.5$ ). (B) Quantitative comparison of cell spreading was obtained by calculating the percentage of spread cells at each time point. (C) Mean cell surface areas were measured by confocal microscopy and quantitative comparisons obtained between macrophages

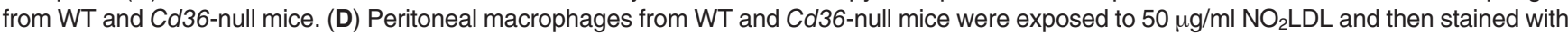
fluorescein-phalloidin to detect polymerized actin. Fluorescence intensity was assayed by flow cytometry. The left histogram shows fluorescence intensity in WT cells with (blue) or without (red) exposure to $\mathrm{NO}_{2} \mathrm{LDL}$, while the right histogram shows fluorescence intensity in Cd36-null cells.

(16). Phosphorylation of FAK was observed at $4^{\circ} \mathrm{C}$, although it was slower than at $37^{\circ} \mathrm{C}$ (Figure 4B). These studies show that internalization of oxLDL is not required for phosphorylation of FAK and suggest a role for direct signaling via CD36.

As we previously demonstrated that oxLDL-CD36 binding activated the Src kinase Lyn in macrophages (16) and as FAK is known to be an Src kinase substrate, we evaluated whether oxLDL-induced FAK phosphorylation was mediated by Src kinases. Macrophages treated with the Src kinase inhibitor 4-amino-5-(4-chlorophenyl)-7(t-butyl)pyrazolo[3,4-d]pyrimidine (PP2), but not a vehicle control, did not show phosphorylation of FAK in response to $\mathrm{NO}_{2} \mathrm{LDL}$ (Figure 4C). We also performed immunoprecipitation of macrophage lysates using an anti-CD36 antibody, and showed by immunoblot that FAK specifically coprecipitated with CD36 (Figure 4D).

To test the effect of FAK on macrophage spreading induced by $\mathrm{NO}_{2} \mathrm{LDL}$, we treated mouse peritoneal macrophages with 2 chemically distinct pharmacological inhibitors of FAK, PF-573,228 and PF-562,271, and showed that both compounds completely blocked the increased spreading response to $\mathrm{NO}_{2} \mathrm{LDL}$ (Figure 5, A and B; $P<0.001)$. The inhibitors did not affect cell viability. In sum, these data show a direct link between oxLDL induced activation of a CD36 signaling complex and macrophage function.

oxLDL induces CD36-dependent inactivation of SHP-2 via generation of ROS. Kinetic studies showed that $\mathrm{NO}_{2} \mathrm{LDL}$ induced sustained phosphorylation of macrophage FAK that persisted for at least 2 hours, while TSP-1, a known FAK activator that did not inhibit migration (25), induced transient phosphorylation lasting less than 30 minutes (Figure 4E). Since the prominent effect of CD36 signaling on FAK was kinetic, we explored the role of the protein tyrosine phosphatase SHP-2 (26), which is known to be a critical regulator of FAK phosphorylation dynamics. We first showed that like FAK, SHP-2 was specifically coprecipitated from macrophage lysates by anti-CD36 antibody (Figure 4D). Next we determined whether sustained phosphorylation of FAK by $\mathrm{NO}_{2} \mathrm{LDL}$ was associated with loss of SHP-2 activity. Phosphorylation of SHP-2 at Tyr580 relieves basal inhibition and stimulates phosphatase activity (27). Using an antibody specific for phospho-Tyr580, we showed by Western blotting that exposure of macrophages to $\mathrm{NO}_{2}$ LDL led to rapid and sustained dephosphorylation of phospho-Tyr580 in WT but not Cd36-null cells. Specific phosphory- 

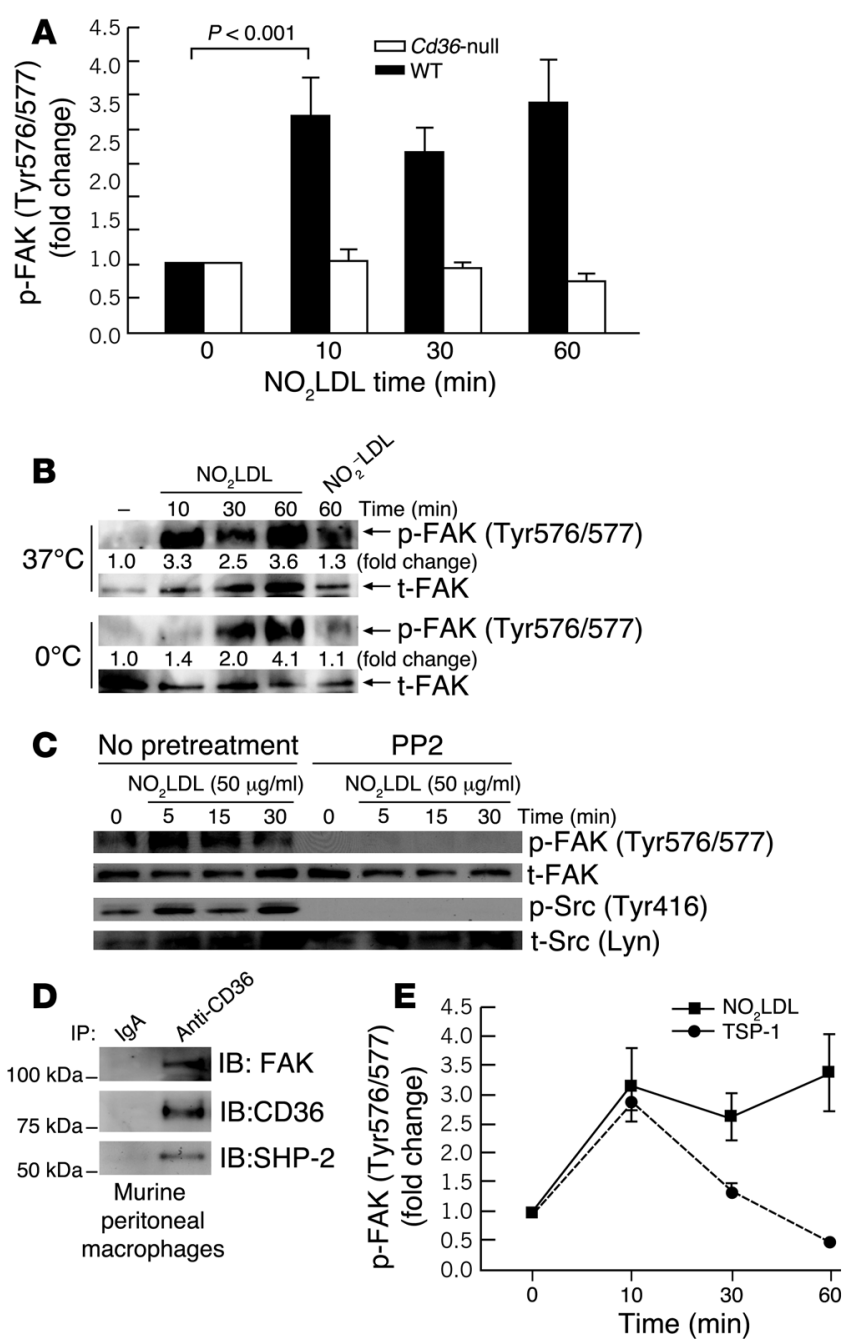

lation was reduced by more than $75 \%$ within 10 minutes and remained low for at least 60 minutes (Figure 6A).

Protein tyrosine phosphatases, including SHP-2, have a critical cysteine residue in their catalytic site that is subject to thiol oxidation. Such oxidation inactivates the enzyme and is a major pathway of regulation. We measured the oxidation status of SHP- 2 after exposure to $\mathrm{NO}_{2} \mathrm{LDL}$ using an assay developed by Wu and Terada (28), in which active enzyme is detected by its ability to be cysteine acetylated by fluorescein-conjugated iodoacetamide. Fluorescein-bound SHP-2 was detected in anti-SHP-2 immunoprecipitates by fluorescence image scanning and showed a marked decrease 5 minutes after cell incubation with $\mathrm{NO}_{2} \mathrm{LDL}$ and near-complete disappearance at 15 minutes (Figure 6B). These data demonstrate that $\mathrm{NO}_{2} \mathrm{LDL}$ induced oxidative modification and inactivation of SHP-2.

Since oxidative modification of protein tyrosine phosphatases is induced by ROS (29), we incubated mouse peritoneal macrophages with $\mathrm{NO}_{2}-\mathrm{LDL}$ or $\mathrm{NO}_{2} \mathrm{LDL}$ and measured ROS generation by staining with $2^{\prime}, 7^{\prime}$-dichlorodihydrofluorescein (DCF). The number of DCF-positive cells was significantly increased by exposure to $\mathrm{NO}_{2} \mathrm{LDL}$ but not $\mathrm{NO}_{2}$-LDL (Figure 7, A and B). Spectrometric quantification of fluorescence staining also revealed that macrophages from WT mice showed significantly more ROS generation in response to $\mathrm{NO}_{2} \mathrm{LDL}$ than macrophages from $\mathrm{Cd} 36$-null mice

\section{Figure 4}

$\mathrm{NO}_{2} \mathrm{LDL}$ induces phosphorylation of macrophage FAK in a CD36and Src kinase-dependent manner, and FAK mediates macrophage spreading in response to $\mathrm{NO}_{2} \mathrm{LDL}$. (A) WT and Cd36-null mouse peritoneal macrophages were exposed to $50 \mu \mathrm{g} / \mathrm{ml} \mathrm{NO} \mathrm{L}_{2} \mathrm{LDL}$ for the indicated times at $37^{\circ} \mathrm{C}$, and then lysates were subjected to Western blot analysis to detect levels of FAK Tyr576/577 phosphorylation using an antibody specific for the phosphorylated form. Immunoblotting with anti-FAK antibody was used for loading control, and fold changes were calculated from scanned images. (B) WT mouse peritoneal macrophages were exposed to $\mathrm{NO}_{2} \mathrm{LDL}$ or $\mathrm{NO}_{2}-\mathrm{LDL}(50 \mu \mathrm{g} / \mathrm{ml})$ at $0^{\circ} \mathrm{C}$ or $37^{\circ} \mathrm{C}$ and examined as in $\mathbf{A}$. (C) Peritoneal macrophages were preincubated with Src kinase inhibitor 4-amino-5-(4-chlorophenyl)-7(t-butyl)pyrazolo[3,4-d]pyrimidine (PP2; $10 \mu \mathrm{M})$ or vehicle control along with $50 \mu \mathrm{g} / \mathrm{ml} \mathrm{NO}_{2} \mathrm{LDL}$ for the indicated times. Cells were then lysed and subjected to immunoblotting to detect FAK Tyr576/577 phosphorylation and Src kinase Tyr416 phosphorylation. (D) Peritoneal macrophages were immunoprecipitated with anti-CD36 antibody or nonimmune $\operatorname{Ig} \mathrm{A}$, and the precipitates were then analyzed by immunoblot using anti-FAK (top), anti-CD36 (middle), and anti-SHP-2 antibodies (bottom). (E) Comparison of FAK Tyr576/577 phosphorylation kinetics in $\mathrm{NO}_{2}$ LDL- (solid line) and TSP-1-treated cells (dashed line).

(Figure 7C). These studies show that oxLDL-induced ROS generation was mediated by CD36.

Inhibition of macrophage ROS generation restores dynamic phosphorylation of FAK and macrophage migration in the presence of oxLDL. To determine whether ROS generation impacts macrophage migration, we tested the effect of antioxidants and NADPH oxidase inhibitors. First, we showed that these agents inhibited macrophage ROS generation induced by $\mathrm{NO}_{2} \mathrm{LDL}$. Macrophages preincubated with antioxidants $N$-acetyl-cysteine (NAC) and resveratrol and NADPH oxidase inhibitors apocynin and diphenyleneiodonium sulfate (DPI) showed greater than $90 \%$ inhibition of DCF staining (Figure 7D) compared with control cells. Second, we performed immunoblots for phosphorylated FAK (Tyr576/577) using macrophages preincubated with $\mathrm{NAC}$ and apocynin before $\mathrm{NO}_{2} \mathrm{LDL}$ treatment and found that both NAC- and apocynin-treated cells showed a brief increase in phosphorylation of FAK, while untreated macrophages had sustained phosphorylation (Figure 8A). Third, we found that macrophage migration in the Boyden chamber in the presence of $\mathrm{NO}_{2} \mathrm{LDL}$ was partially restored when cells were pretreated with antioxidants or NADPH oxidase inhibitors to restore dynamic FAK activation (Figure 8B).

\section{Discussion}

Previous studies of atherosclerotic plaque progression and regression have revealed the dynamic nature of atherosclerotic lesions and the important role of macrophage neointimal trapping in lesion growth and macrophage emigration to regional lymph nodes in lesion regression $(10,11,30-32)$. The mechanisms involved in macrophage trapping in the inflamed atherosclerotic neointima are incompletely understood yet represent a novel target for potential therapeutic intervention. In this article, we report that CD36mediated signals generated in macrophages exposed to oxLDL may be important contributors to this process. CD36 is a transmembrane glycoprotein receptor expressed in monocytes/macrophages, immature dendritic cells, platelets, microvascular endothelial cells, and adipocytes (33). Macrophage CD36 plays a critical role in foam cell formation by mediating recognition and uptake of oxLDL $(16,34,35)$. Previous studies from our laboratory and others have 
A
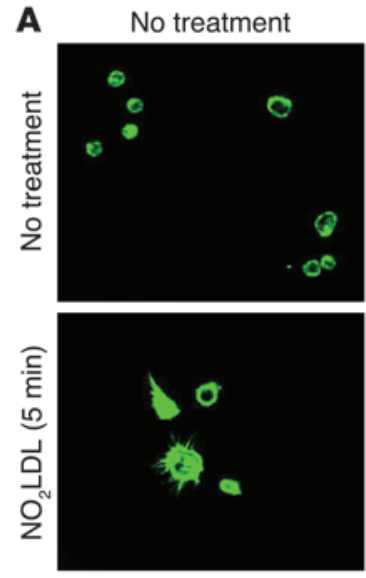

PF-573,228

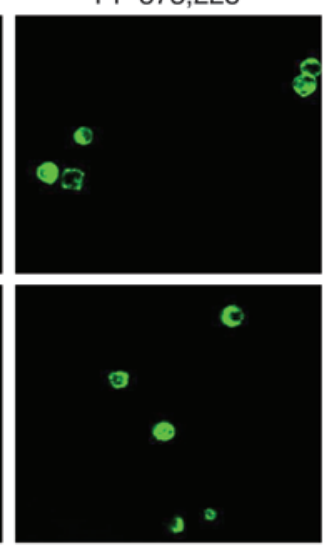

PF-562,271

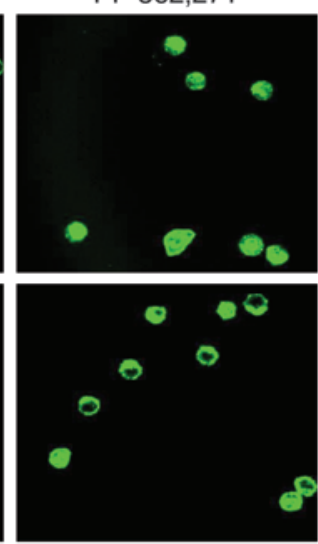

B

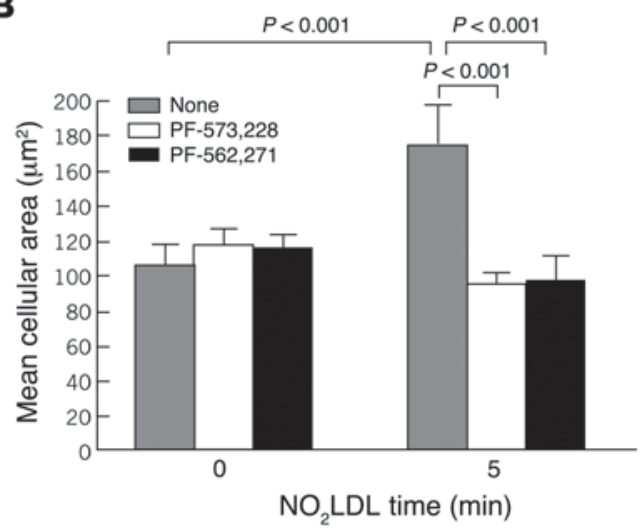

Figure 5

FAK mediates macrophage spreading in response to $\mathrm{NO}_{2} \mathrm{LDL}$. (A) Mouse peritoneal macrophages were preincubated with FAK inhibitors (PF573,228 and PF-562,271; $10 \mu \mathrm{M}$ for each) for 1 hour and incubated with or without $\mathrm{NO}_{2} \mathrm{LDL}$ at $37^{\circ} \mathrm{C}$. Cells were photographed after 5 minutes (original magnification, $\times 94.5$ ). (B) Mean cellular area was measured by confocal microscopy, and quantitative comparisons between FAK inhibitor-treated and untreated cells were obtained.

shown that Cd36-null macrophages have a severe defect in foam cell formation in vitro and in vivo (12, 36-39). Furthermore, atherosclerosis in Apoe-null mice fed a high-fat "Western" diet was significantly inhibited by concomitant genetic deletion of CD36 $(12,13)$, pharmacologic interference with CD36-oxLDL interactions (40), or transplantation of Cd36-null bone marrow (15). We now show that in addition to mediating foam cell formation, CD36 may promote atherosclerosis by modulating macrophage cytoskeletal dynamics, thereby inhibiting emigration from lesions.

The in vivo macrophage peritoneal efflux model used in these studies is an appropriate system to probe the effects of oxLDL on macrophage emigration from inflammatory lesions for several reasons. First, factors influencing monocyte recruitment are eliminated; all studies begin with similar number of cells in the peritoneal cavity. Second, as with emigration of macrophages from atherosclerotic lesions, in this model the fate of the emigrating peritoneal cells is transit to regional lymph nodes (18). It is interesting that while abrogation of CD36 only partially restored macrophage migration in the presence of oxLDL in in vitro migration assays, it completely restored migration in the in vivo model.

Although CD36 has extremely short cytoplasmic domains, it has been shown to function as a signaling molecule in macrophages (16), microglial cells (17), endothelial cells (41), and platelets (42,

\section{Figure 6}

Inactivation of SHP-2 by $\mathrm{NO}_{2} \mathrm{LDL}$. (A) Peritoneal macrophages from WT and Cd36-null mice were exposed to $50 \mu \mathrm{g} / \mathrm{ml} \mathrm{NO} 2 \mathrm{LDL}$ for the indicated times. Western blot analysis of lysates was performed with an antibody against phospho-SHP-2 (Tyr580) (upper blots) and total SHP-2 (t-SHP-2; lower blots). Dephosphorylation of SHP-2 was rapid and sustained in WT but not Cd36-null cells. (B) Lysates from macrophages incubated with $\mathrm{NO}_{2} \mathrm{LDL}$ for the indicated time periods were incubated with 5-F-IAA to acetylate available cysteine residues. Cell lysates were then immunoprecipitated with anti-SHP-2 antibody and analyzed by SDS-PAGE. The fluoresceinated SHP-2 band was detected by in situ fluorescence scanning of the gel. Decreased band intensity of fluoresceinated SHP-2 indicates time-dependent oxidation of the active site cysteine and inactivation of SHP-2.
43). In these cells, CD36 ligands, such as oxLDL, TSP-1, bacterial cell wall components, and amyloid $\mathrm{A} \beta$, have been shown to induce signaling cascades that involve recruitment and activation of the Src family tyrosine kinases Fyn and/or Lyn, with subsequent activation of specific MAP kinases including p38 and JNK2. In macrophages, pharmacologic blockade of Lyn or JNK inhibited CD36mediated foam cell formation, while in microvascular endothelial cells, blockade of p38 or Fyn inhibited CD36-mediated antiangiogenic responses $(16,41)$. In this article, we show for the first time to our knowledge that oxLDL-mediated CD36 signals led to enhanced actin polymerization associated with sustained phos-

A
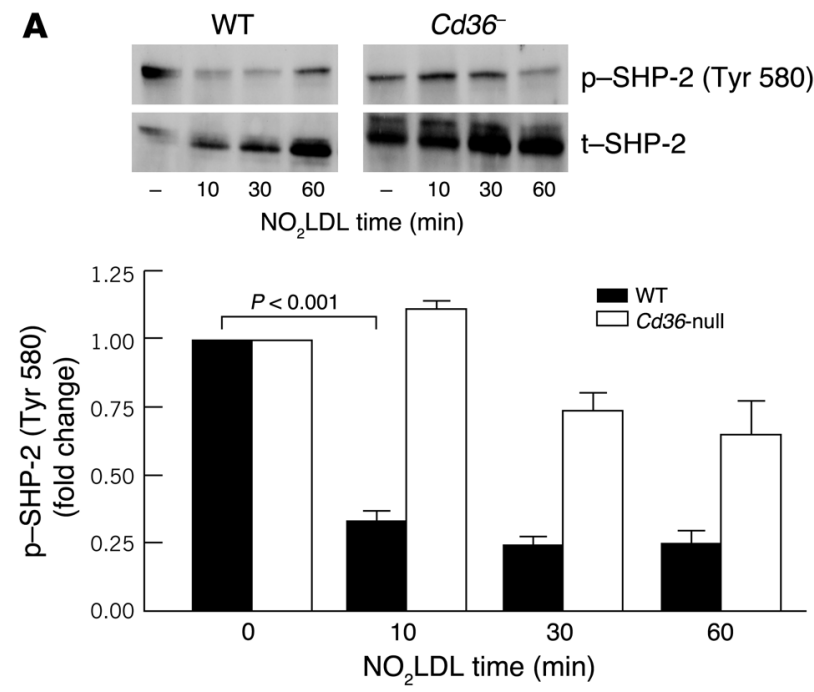

B

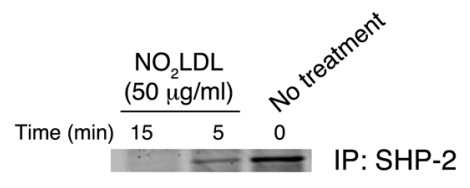

Fluorescein-bound SHP-2 
A

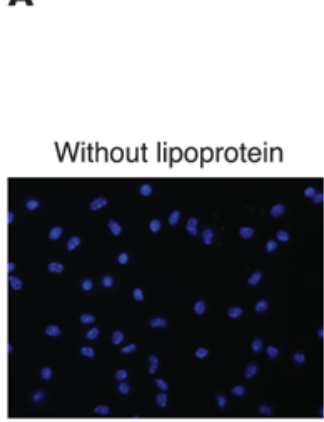

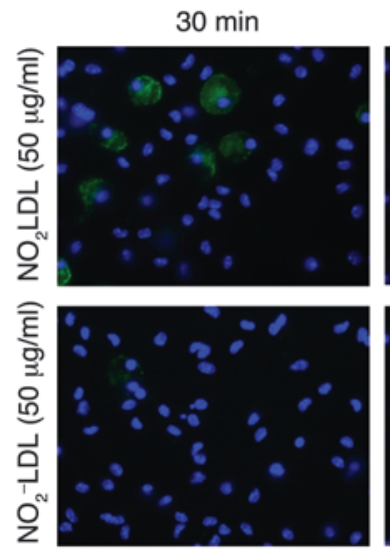
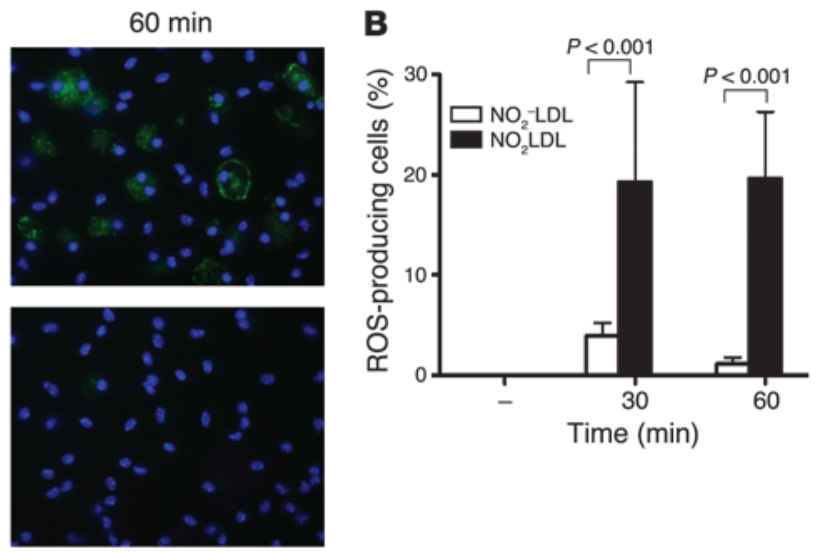

C
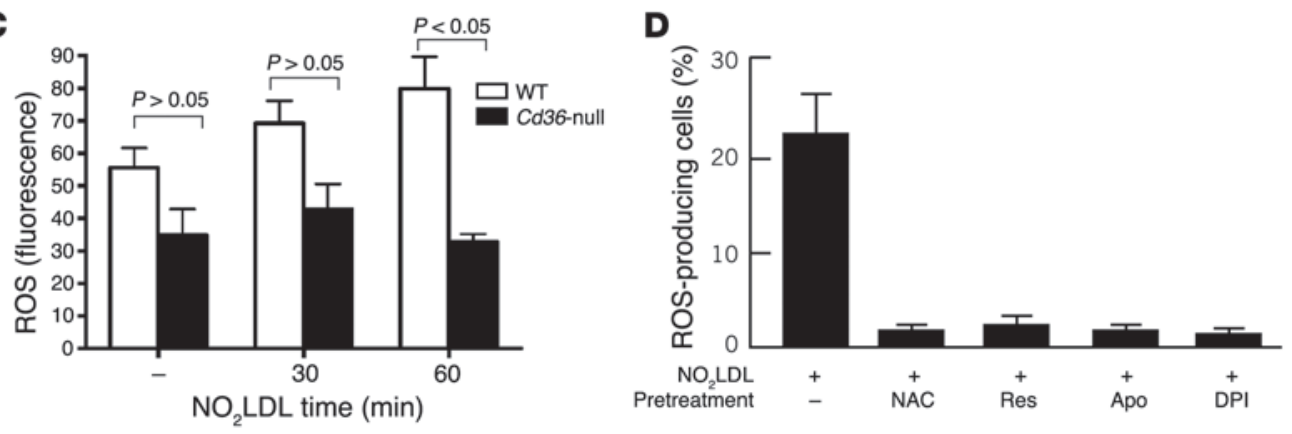

Figure 7

Macrophage exposure to $\mathrm{NO}_{2} \mathrm{LDL}$ induces generation of ROS in a CD36-dependent manner. (A) Peritoneal macrophages were exposed to 50 $\mu \mathrm{g} / \mathrm{ml} \mathrm{NO} \mathrm{LDL}_{2}$ or $\mathrm{NO}_{2}-\mathrm{LDL}$ for 30 and 60 minutes. ROS were then detected with the fluorescent probe 5-(and-6)-carboxy-2',7'-dichlorodihydrofluorescein diacetate (carboxy- $\mathrm{H}_{2}$ DCFDA) by fluorescence microscopy (original magnification, $\times 40$ ). Quantification by counting fluorescent cells is shown in B. (C) Fluorimetric quantification of ROS generation in a separate study comparing macrophages from WT with those from Cd36-null mice. (D) Peritoneal macrophages were pretreated with antioxidants $(20 \mathrm{mM} \mathrm{NAC}$ and $100 \mu \mathrm{M}$ resveratrol) or NADPH oxidase inhibitors (10 $\mu \mathrm{M}$ apocynin and $4 \mu \mathrm{M} \mathrm{DPI}$ ) and then exposed to $50 \mu \mathrm{g} / \mathrm{ml} \mathrm{NO}_{2} \mathrm{LDL}$. ROS were detected as in A and B. Res, resveratrol; Apo, apocynin.

phorylation of Tyr576/577 in the active site of FAK. Direct phosphorylation by Src family kinases likely contributes to FAK activation in this setting (24), as our experiments revealed that Src kinase inhibitors blocked FAK activation by oxLDL. As previous reports revealed that $\mathrm{CD} 36$ physically associates with integrins and may form a functional receptor complex $(44,45)$, it is possible that integrins are also involved in FAK activation by oxLDL-CD36 interaction. We also showed that oxLDL interactions with CD36 led to inactivation of SHP-2, the major inactivating phosphatase for FAK. The mechanism of SHP-2 inactivation was shown to be oxidative modification of the catalytic site. Previous reports have shown that oxidative inactivation of protein tyrosine phosphatases, including protein tyrosine phosphatase-1B (PTP1B), SHP-2, phosphatase and tensin homolog (PTEN), and low-molecular-weight protein tyrosine phosphatase (LM-PTP), could be induced by intracellular ROS generated in response to specific receptor-mediated signaling pathways, such as those initiated by EGFR, PDGFR, and TCR $(29,46-49)$. Our studies showed that oxLDL-CD36 interactions in macrophages led to NADPH oxidase-mediated generation of intracellular ROS and that pharmacologic blockade of NADPH oxidase or treatment with antioxidants restored the dynamic activation of FAK and thus abrogated the antimigratory effect of CD36. These findings suggest that CD36 ligands generate downstream signals via intracellularly generated ROS.
The cell migration process consists of actin polymerizationdriven lamellipodia extension, disruption of existing focal contacts, and formation of new focal contacts (22). Thus, a regulated balance between cytoskeletal assembly and disassembly must be maintained to ensure cell movement. Loss of tyrosine phosphorylation of FAK is temporally associated with disruption of focal adhesions and acquisition of a motile phenotype (50), suggesting that agonists that induce rapid, short-lived activation of FAK will promote migration (25), while agonists that result in sustained activation (such as oxLDL) may inhibit migration. Our data are consistent with previous reports that revealed that FAK hyperphosphorylation in cells deficient in SHP-2 activity was associated with impaired migration $(26,51)$. By showing that the migration-inhibitory function of oxLDL followed from perturbation of reversible phosphorylation of FAK, we confirmed the importance of highly coordinated dynamic cytoskeletal signaling in regulating cell migration. Our studies with FAK and ROS inhibitors also suggest that functional changes induced by oxLDL-CD36 interaction were directly related to the CD36-mediated signaling.

In summary, as shown in the model in Figure 9, our studies have defined what we believe to be a previously unknown macrophage signaling pathway triggered by oxLDL interaction with CD36. The newly described effectors of this pathway, FAK and SHP-2, appear to exert their effect through physical association with CD36. This 


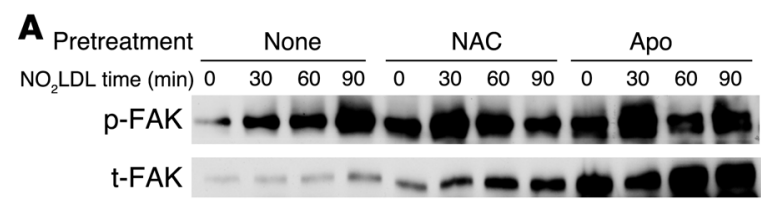

B

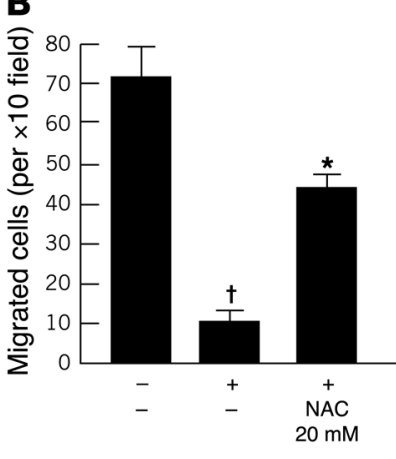

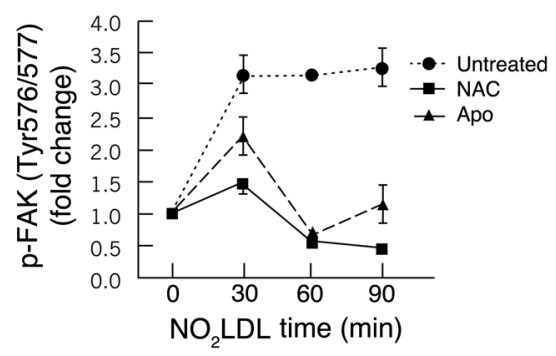

\section{Figure 8}

Antioxidants and NADPH oxidase inhibitors restore dynamic activation of FAK and macrophage migration. (A) Peritoneal macrophages were

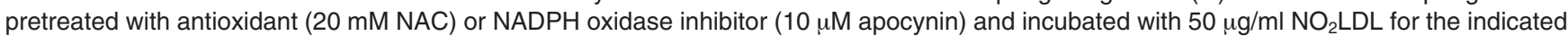
times. Cells were then lysed and subjected to immunoblotting to detect FAK Tyr576/577 phosphorylation. (B) Peritoneal macrophages were pretreated with antioxidants or NADPH oxidase inhibitors and then loaded into a Boyden chamber with $\mathrm{NO}_{2} \mathrm{LDL}$. Migrated macrophages were counted after 16 hours as described in Figure $2 .{ }^{\dagger} P<0.05,{ }^{\star} P>0.05$ compared with no treatment.

pathway involves NADPH oxidase-mediated generation of ROS that in turn leads to oxidative inactivation of SHP-2. SHP-2 inactivation coupled with Src family kinase activation results in sustained phosphorylation of FAK and increased actin polymerization. Thus, the net effect of this pathologic CD36 signaling cascade is enhancement of cell spreading and inhibition of migration. These studies provide a mechanistic explanation for oxLDL-induced macrophage trapping in atheroinflammatory lesions and suggest novel ways to promote mobilization and emigration of macrophages. They also provide additional mechanistic support for the atheroprotective effect of antioxidants $(52,53)$ and CD36 deficiency (12-15).

\section{Methods}

Reagents and antibodies. LDL prepared from human plasma by density gradient ultracentrifugation (54) was oxidatively modified using 2 different methods. $\mathrm{NO}_{2} \mathrm{LDL}$ was generated using the MPO-hydrogen peroxidenitrite system described previously (35). $\mathrm{Cu}^{2+}$ oxLDL was generated by dialysis with $5 \mu \mathrm{M} \mathrm{CuSO}_{4}$ in $\mathrm{PBS}$ for 6 hours at $37^{\circ} \mathrm{C}$. Oxidation was terminated by dialysis against PBS containing EDTA $(100 \mu \mathrm{M})$. Ac-LDL and PMA were purchased from Invitrogen. LPS, 5-fluorescein-iodoacetamide (5-F-IAA), NAC, resveratrol, apocynin, and DPI were purchased from Sigma-Aldrich.

\section{Figure 9}

Model depicting CD36-dependent mechanism of macrophage trapping in the neointima. oxLDL interacts with CD36 to induce a signaling cascade that leads to activation of specific Src kinases (e.g., Lyn), which in turn phosphorylate and activate FAK and lead to actin polymerization. oxLDL interactions with CD36 also lead to NADPH oxidase-mediated generation of intracellular ROS, which in turn induce oxidative inactivation of SHP-2, resulting in sustained FAK activation that perturbs cytoskeletal disassembly. The net effects are enhancement of cell spreading with concomitant inhibition of migration and therefore trapping of cells in the neointima. PTP, protein tyrosine phosphatase.
Antibodies against Tyr576/577 p-FAK, FAK, Tyr580 phospho-SHP-2, and SHP-2 were purchased from Cell Signaling Technology. Anti-fluorescein antibody, fluorescein-conjugated phalloidin, and 5-(and-6)-carboxy-2', $7^{\prime}$ dichlorodihydrofluorescein diacetate (carboxy- $\mathrm{H}_{2} \mathrm{DCFDA}$ ) were purchased from Invitrogen. Anti- $\beta$-tubulin and PE-conjugated anti-Mac- 1 antibodies were purchased from Abcam. Anti-neutrophil antibody MCA771FA was purchased from AbD Serotec. PE-conjugated annexin V apoptosis detection kit was purchased from $\mathrm{BD}$ Biosciences - Pharmingen. FAK inhibitors (PF-573,228 and PF-562,271) were provided by Pfizer. Src kinase inhibitor PP2 was purchased from Calbiochem. CNBr-activated sepharose 4B was purchased from GE Healthcare.

Animals and cells. All animal studies were approved by the Institutional Animal Care and Utilization Committee of Cleveland Clinic. Cd36-null mice

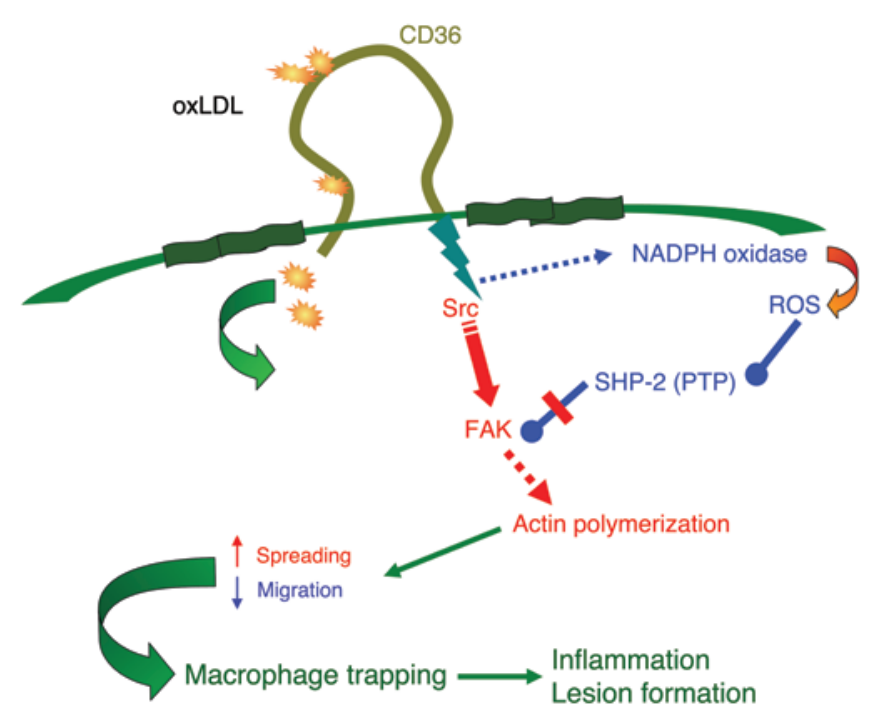


generated by targeted homologous recombination were described previously (55) and were backcrossed such that they were genetically more than 98\% C57BL/6. Littermate-derived background-matched mice were used as controls. Mouse peritoneal macrophages were collected by lavage 4 days after intraperitoneal injection of thioglycollate $(1 \mathrm{ml}, 4 \%)$. Cells were cultured in RPMI containing 10\% FBS. The human monocyte cell line THP-1 was obtained from ATCC. Human monocytes were isolated from peripheral blood by Ficoll-Hypaque centrifugation and were cultured in RPMI containing human bovine serum (10\%) for 7 days for macrophage differentiation.

In vivo migration assay. To demonstrate the effect of lipoproteins on mouse macrophage migration, we modified the macrophage efflux model previously described by Cao et al. (18). WT and Cd36-null mice were injected intraperitoneally with $1 \mathrm{ml}$ of $4 \%$ thioglycollate. After 5 days, the mice were injected intraperitoneally with PBS, $\mathrm{NO}_{2}-\mathrm{LDL}(50 \mu \mathrm{g})$, or $\mathrm{NO}_{2} \mathrm{LDL}(50 \mu \mathrm{g})$, and 1 hour later they were injected with LPS $(250 \mu \mathrm{l} ; 5 \mu \mathrm{g} / \mathrm{ml})$. After 4 hours, the peritoneal cells were collected by lavage and counted using a Beckman Coulter particle counter. The percentage of macrophages in the lavage was quantified by flow cytometry with PE-conjugated anti-Mac-1 antibody. Macrophage count was plotted as migration index. Migration index is defined as [ 1 - (peritoneal macrophage count from each animal/average number of peritoneal macrophages of the thioglycollate-only control group mice) $] \times 100$ (\%). Significance was determined using ANOVA followed by Bonferroni's multiple comparison test. Polymorphonuclear neutrophils in the lavage staining for Mac-1 were detected using a specific anti-neutrophil antibody and accounted for less than $1 \%$ of the total population.

In vitro migration assay (modified Boyden chamber migration assay). Migration of mouse peritoneal macrophages, human peripheral blood-derived macrophages, and PMA-treated THP-1 cells was measured in a modified Boyden chamber migration assay using Transwell inserts with a $5 \mu \mathrm{m}$ porous membrane (Corning) or the Chemicon QCM 96-well (5 $\mu \mathrm{m}$ ) Cell Migration Assay kit (Millipore). Cells were loaded into the migration chamber with various lipoproteins, including $\mathrm{NO}_{2}-\mathrm{LDL}, \mathrm{NO}_{2} \mathrm{LDL}$, and $\mathrm{Cu}^{2+}$ oxLDL. Medium containing $10 \mathrm{ng} / \mathrm{ml} \mathrm{MCP-1}$ was placed in the lower chamber in some studies. After allowing cell migration for 16 hours, cells were removed from the upper side of membranes, and nuclei of migratory cells on the lower side of the membrane were stained with DAPI. The number of migratory cells was determined by fluorescence microscopy. To evaluate the effect of antioxidants and NADPH oxidase inhibitors on macrophage migration, cells were pretreated with NAC $(20 \mathrm{mM})$, resveratrol $(100 \mu \mathrm{M})$, DPI $(0.5 \mu \mathrm{M}, 2 \mu \mathrm{M}$, and $4 \mu \mathrm{M})$, or apocynin $(2 \mu \mathrm{M}, 10 \mu \mathrm{M}$, and $100 \mu \mathrm{M})$ for 1 hour prior to loading onto the migration chamber.

Cell spreading assay. Mouse peritoneal macrophages were placed onto serum-coated coverslips at $37^{\circ} \mathrm{C}$. After 30 minutes to allow macrophages to adhere to the surface, $50 \mu \mathrm{g} / \mathrm{ml}$ of $\mathrm{NO}_{2}-\mathrm{LDL}$ or $\mathrm{NO}_{2} \mathrm{LDL}$ was added. After the indicated incubation times, cells were fixed with $4 \%$ paraformaldehyde and stained with fluorescein-conjugated phalloidin. Spread cells were counted using a Leica TCS SP2 spectral laser confocal microscope (Leica Microsystems), and the cell surface areas were measured using Image-Pro Plus software (Media Cybernetics). In some studies, macrophages were incubated with specific FAK inhibitors (PF-573,228 and PF-562,271) at $10 \mu \mathrm{M}$ for 1 hour prior to addition of $\mathrm{NO}_{2} \mathrm{LDL}$.

Flow cytometry assays. To quantify apoptosis in peritoneal macrophages in the in vivo migration studies, $10^{5}$ cells were rinsed with PBS, incubated with $\mathrm{PE}$-annexin $\mathrm{V}$ and 7-AAD at room temperature for 15 minutes in the dark, and then counted by flow cytometry using a BD FACScan. Data were analyzed by CellQuest version 3.3 (BD). To quantify neutrophils in the mouse peritoneal exudate, cells were coincubated with FITC-conjugated anti-neutrophil antibody (MCA771FA; AbD Serotec) and PE-conjugated anti-Mac-1 antibody. MCA771FA-positive cells were counted as above and were less than $1 \%$ of the total Mac-1-positive pool. To detect polymerized actin (F-actin), mouse peritoneal macrophages were incubated with $\mathrm{NO}_{2}-\mathrm{LDL}, \mathrm{NO}_{2} \mathrm{LDL}$, or $\mathrm{Cu}^{2+}$ oxLDL at $37^{\circ} \mathrm{C}$. After the indicated times, cells were fixed with $4 \%$ paraformaldehyde and stained with fluorescein-conjugated phalloidin. Fluorescence intensity was quantified by flow cytometry using a Guava PCA-96 System (Guava Technologies), and data were analyzed by FlowJo software (Tree Star).

Western blot analysis. Mouse peritoneal macrophages incubated with 50 $\mu \mathrm{g} / \mathrm{ml} \mathrm{NO}_{2}-\mathrm{LDL}$ or $\mathrm{NO}_{2} \mathrm{LDL}$ for the indicated times were lysed in $20 \mathrm{mM}$ Tris- $\mathrm{HCl}$ (pH 7.5), $150 \mathrm{mM} \mathrm{NaCl}, 1 \mathrm{mM}$ EDTA, 1 mM EGTA, 1\% NP-40, $2.5 \mathrm{mM}$ sodium pyrophosphate, $1 \mathrm{mM} \beta$-glycerophosphate, $1 \mathrm{mM}$ sodium orthovanadate. Clarified lysates were separated by SDS-PAGE and transferred to PVDF membranes (Millipore). Membranes were probed with antibodies against p-FAK or phospho-SHP-2. After chemiluminescence detection, membranes were stripped with $0.2 \mathrm{M}$ sodium hydroxide and reprobed with antibodies against $\beta$-tubulin, FAK, or SHP-2 for normalization. Band intensities were quantified by ImageJ (http://rsbweb.nih.gov/ij/) and GelPro Analyzer (MediaCybernetics).

Oxidative modification assay. Oxidative modification of the active site thiol group of SHP-2 was evaluated as described by Wu et al. (28). Mouse peritoneal macrophages incubated with $\mathrm{NO}_{2}-\mathrm{LDL}$ or $\mathrm{NO}_{2} \mathrm{LDL}$ were lysed as described above, and $100 \mu \mathrm{g}$ of protein from each lysate was exposed to 5-F-IAA for 1 hour at room temperature. For immunoprecipitation, agarose beads (CNBr-activated sepharose 4B; GE Healthcare) were coupled with anti-SHP-2 antibody following the manufacturer's instruction. Proteins were incubated with anti-SHP-2 antibody-coupled beads and separated by SDS-PAGE. Fluorescein-bound SHP-2 was detected by fluorescence scanning of the gel (Typhoon Trio; GE Healthcare). The proteins in the gel were then transferred to a membrane and immunoblotted with an antibody against SHP-2.

ROS detection. Mouse peritoneal macrophages were plated on coverslips or in 96-well plates and incubated with $\mathrm{NO}_{2}-\mathrm{LDL}$ or $\mathrm{NO}_{2} \mathrm{LDL}$. After the indicated times, cells were washed and stained with carboxy- $\mathrm{H}_{2} \operatorname{DCFDA}(25 \mu \mathrm{M})$ for 30 minutes at $37^{\circ} \mathrm{C}$. Nuclei were counterstained with Hoechst 33342 . Fluorescently labeled cells were counted by microscopy (Leica DMR; Leica Microsystems), and fluorescence intensity was measured with a 96-well fluorescence plate reader (SpectraMax Gemini EM; Molecular Devices).

Statistics. We performed ANOVA followed by Bonferroni's multiple comparison test. A $P$ value less than 0.05 was considered significant. Data are expressed as mean \pm SD. The analyses were formed using GraphPad Prism Software.

\section{Acknowledgments}

This work was supported by National Heart, Lung, and Blood Institute grants PO1 HL46403 and PO1 HL087018 to R.L. Silverstein and R01 HL 70083 to M. Febbraio We thank David Kennedy and David Schmitt in the Cleveland Clinic Department of Cell Biology for their assistance in preparing $\mathrm{NO}_{2} \mathrm{LDL}$.

Received for publication March 6, 2008, and accepted in revised form October 29, 2008.

Address correspondence to: Roy L. Silverstein, Department of Cell Biology (NC10), Lerner Research Institute, Cleveland Clinic Foundation, 9500 Euclid Avenue, Cleveland, Ohio 44195, USA. Phone: (216) 444-5220; Fax: (216) 444-9404; E-mail: silverr2@ccf.org.
1. Murray, C.J., and Lopez, A.D. 1997. Global mortality, disability, and the contribution of risk factors: Global Burden of Disease Study. Lancet. 349:1436-1442.
2. Lusis, A.J. 2000. Atherosclerosis. Nature. 407:233-241.

3. Libby, P. 2002. Inflammation in atherosclerosis. Nature. 420:868-874.
4. Platt, N., and Gordon, S. 2001. Is the class A macrophage scavenger receptor (SR-A) multifunctional? - the mouse's tale. J. Clin. Invest. 108:649-654. 
5. Silverstein, R.L., and Febbraio, M. 2000. CD36 and atherosclerosis. Curr. Opin. Lipidol. 11:483-491.

6. Angeli, V., et al. 2004. Dyslipidemia associated with atherosclerotic disease systemically alters dendritic cell mobilization. Immunity. 21:561-574.

7. Pentikainen, M.O., Oksjoki, R., Oorni, K., and Kovanen, P.T. 2002. Lipoprotein lipase in the arterial wall: linking LDL to the arterial extracellular matrix and much more. Arterioscler. Thromb. Vasc. Biol. 22:211-217.

8. Watanabe, N., and Ikeda, U. 2004. Matrix metalloproteinases and atherosclerosis. Curr. Atheroscler. Rep. 6:112-120.

9. Taubman, M.B., et al. 1997. Tissue factor in the pathogenesis of atherosclerosis. Thromb. Haemost. 78:200-204.

10. Daoud, A.S., Jarmolych, J., Augustyn, J.M., and Fritz, K.E. 1981. Sequential morphologic studies of regression of advanced atherosclerosis. Arch. Pathol. Lab. Med. 105:233-239.

11. Llodra, J., et al. 2004. Emigration of monocytederived cells from atherosclerotic lesions characterizes regressive, but not progressive, plaques. Proc. Natl. Acad. Sci. U. S. A. 101:11779-11784.

12. Febbraio, M., et al. 2000. Targeted disruption of the class B scavenger receptor CD36 protects against atherosclerotic lesion development in mice. J. Clin. Invest. 105:1049-1056.

13. Guy, E., Kuchibhotla, S., Silverstein, R.L., and Febbraio, M. 2007. Continued inhibition of atherosclerotic lesion development in long term Western diet fed $\mathrm{CD} 36^{\circ} / \mathrm{apoE}^{\circ}$ mice. Atherosclerosis. 192:123-130.

14. Kuchibhotla, S., et al. 2008. Absence of CD36 protects against atherosclerosis in ApoE knock-out mice with no additional protection provided by absence of scavenger receptor A I/II. Cardiovasc. Res. 78:185-196.

15. Febbraio, M., Guy, E., and Silverstein, R.L. 2004. Stem cell transplantation reveals that absence of macrophage CD36 is protective against atherosclerosis. Arterioscler. Thromb. Vasc. Biol. 24:2333-2338.

16. Rahaman, S.O., et al. 2006. A CD36-dependent signaling cascade is necessary for macrophage foam cell formation. Cell Metab. 4:211-221.

17. Moore, K.J., et al. 2002. A CD36-initiated signaling cascade mediates inflammatory effects of betaamyloid. J. Biol. Chem. 277:47373-47379.

18. Cao, C., Lawrence, D.A., Strickland, D.K., and Zhang, L. 2005. A specific role of integrin Mac-1 in accelerated macrophage efflux to the lymphatics. Blood. 106:3234-3241.

19. Podrez, E.A., et al. 2000. Macrophage scavenger receptor CD36 is the major receptor for LDL modified by monocyte-generated reactive nitrogen species. J. Clin. Invest. 105:1095-1108.

20. Dawson, D.W., et al. 1997. CD36 mediates the in vitro inhibitory effects of thrombospondin-1 on endothelial cells. J. Cell. Biol. 138:707-717.

21. Simantov, R., and Silverstein, R.L. 2003. CD36: a critical anti-angiogenic receptor. Front. Biosci. 8:s874-s882.

22. Stossel, T.P. 1994. The machinery of cell crawling. Sci. Am. 271:54-63.

23. Small, J.V., Stradal, T., Vignal, E., and Rottner, K.
2002. The lamellipodium: where motility begins. Trends Cell. Biol. 12:112-120.

24. Calalb, M.B., Polte, T.R., and Hanks, S.K. 1995. Tyrosine phosphorylation of Focal adhesion kinase at sites in the catalytic domain regulates kinase activity: a role for Src family kinases. Mol. Cell. Biol. 15:954-963.

25. Orr, A.W., Pallero, M.A., Xiong, W.C., and MurphyUllrich, J.E. 2004. Thrombospondin induces RhoA inactivation through FAK-dependent signaling to stimulate focal adhesion disassembly. J. Biol. Chem. 279:48983-48992.

26. Yu, D., Qu, C.K., Henegariu, O., Lu, X., and Feng, G.S. 1998. Protein-tyrosine phosphatase Shp-2 regulates cell spreading, migration, and focal adhesion. J. Biol. Chem. 273:21125-21131.

27. Lu, W., Gong, D., Bar-Sagi, D., and Cole, P.A. 2001. Site-specific incorporation of a phosphotyrosine mimetic reveals a role for tyrosine phosphorylation of SHP-2 in cell signaling. Mol. Cell. 8:759-769.

28. Wu, R.F., and Terada, L.S. 2006. Oxidative modification of protein tyrosine phosphatases. Sci. STKE. 2006:pl2.

29. Meng, T.C., Fukada, T., and Tonks, N.K. 2002. Reversible oxidation and inactivation of protein tyrosine phosphatases in vivo. Mol. Cell. 9:387-399.

30. Wissler, R.W., and Vesselinovitch, D. 1976. Studies of regression of advanced atherosclerosis in experimental animals and man. Ann. N. Y. Acad. Sci. 275:363-378.

31. Malinow, M.R. 1983. Experimental models of atherosclerosis regression. Atherosclerosis. 48:105-118.

32. Reis, E.D., et al. 2001. Dramatic remodeling of advanced atherosclerotic plaques of the apolipoprotein E-deficient mouse in a novel transplantation model. J. Vasc. Surg. 34:541-547.

33. Febbraio, M., Hajjar, D.P., and Silverstein, R.L. 2001. CD36: a class B scavenger receptor involved in angiogenesis, atherosclerosis, inflammation, and lipid metabolism. J. Clin. Invest. 108:785-791.

34. Endemann, G., et al. 1993. CD36 is a receptor for oxidized low density lipoprotein. J. Biol. Chem. 268:11811-11816.

35. Podrez, E.A., Schmitt, D., Hoff, H.F., and Hazen, S.L. 1999. Myeloperoxidase-generated reactive nitrogen species convert LDL into an atherogenic form in vitro. J. Clin. Invest. 103:1547-1560.

36. Nozaki, S., et al. 1995. Reduced uptake of oxidized low density lipoproteins in monocyte-derived macrophages from CD36-deficient subjects. J. Clin. Invest. 96:1859-1865.

37. Podrez, E.A., et al. 2002. A novel family of atherogenic oxidized phospholipids promotes macrophage foam cell formation via the scavenger receptor CD36 and is enriched in atherosclerotic lesions. J. Biol. Chem. 277:38517-38523.

38. Kunjathoor, V.V., et al. 2002. Scavenger receptors class A-I/II and CD36 are the principal receptors responsible for the uptake of modified low density lipoprotein leading to lipid loading in macrophages. J. Biol. Chem. 277:49982-49988.

39. Zhao, A., et al. 2005. Low-density lipoprotein from apolipoprotein E-deficient mice induces macrophage lipid accumulation in a CD36 and scavenger receptor class A-dependent manner. Arterioscler. Thromb. Vasc. Biol. 25:168-173.

40. Marleau, S., et al. 2005. EP 80317, a ligand of the CD36 scavenger receptor, protects apolipoprotein E-deficient mice from developing atherosclerotic lesions. FASEB J. 19:1869-1871.

41. Jimenez, B., et al. 2000. Signals leading to apoptosis-dependent inhibition of neovascularization by thrombospondin-1. Nat. Med. 6:41-48.

42. Podrez, E.A., et al. 2007. Platelet CD36 links hyperlipidemia, oxidant stress and a prothrombotic phenotype. Nat. Med. 13:1086-1095.

43. Huang, M.M., Bolen, J.B., Barnwell, J.W., Shattil, S.J., and Brugge, J.S. 1991. Membrane glycoprotein IV (CD36) is physically associated with the Fyn, Lyn, and Yes protein-tyrosine kinases in human platelets. Proc. Natl. Acad. Sci. U. S. A. 88:7844-7848.

44. Miao, W., Vasile, E., Lane, W.S., and Lawler, J. 2001. CD36 associates with CD9 and integrins on human blood platelets. Blood. 97:1689-1696.

45. Bamberger, M.E., Harris, M.E., McDonald, D.R., Husemann, J., and Landreth, G.E. 2003. A cell surface receptor complex for fibrillar beta-amyloid mediates microglial activation. J. Neurosci. 23:2665-2674.

46. Lee, S.R., Kwon, K.S., Kim, S.R., Rhee, S.G. 1998. Reversible inactivation of protein-tyrosine phosphatase 1B in A431 cells stimulated with epidermal growth factor. J. Biol. Chem. 273:15366-15372.

47. Chiarugi, P., et al. 2001. Two vicinal cysteines confer a peculiar redox regulation to low molecular weight protein tyrosine phosphatase in response to platelet-derived growth factor receptor stimulation. J. Biol. Chem. 276:33478-33487.

48. Kwon, J., et al. 2004. Reversible oxidation and inactivation of the tumor suppressor PTEN in cells stimulated with peptide growth factors. Proc. Natl. Acad. Sci. U. S. A. 101:16419-16424.

49. Kwon, J., Qu, C.K., Maeng, J.S., Falahati, R., Lee, C. and Williams, M.S. 2005. Receptor-stimulated oxidation of SHP-2 promotes T-cell adhesion through SLP-76-ADAP. EMBO J. 24:2331-2341.

50. Matsumoto, K., Matsumoto, K., Nakamura, T., and Kramer, R.H. 1994. Hepatocyte growth factor/scatter factor induces tyrosine phosphorylation of focal adhesion kinase ( $\mathrm{p} 125 \mathrm{FAK}$ ) and promotes migration and invasion by oral squamous cell carcinoma cells. J. Biol. Chem. 269:31807-31813.

51. Manes, S., et al. 1999. Concerted activity of tyrosine phosphatase SHP-2 and focal adhesion kinase in regulation of cell motility. Mol. Cell Biol. 19:3125-3135

52. Bjorkhem, I., et al. 1991. The antioxidant butylated hydroxytoluene protects against atherosclerosis. Arterioscler. Thromb. 11:15-22.

53. Rimm, E.B., et al. 1993. Vitamin E consumption and the risk of coronary heart disease in men. N. Engl. J. Med. 328:1450-1456.

54. Hatch, F.T. 1968. Practical methods for plasma lipoprotein analysis. Adv. Lipid Res. 6:1-68.

55. Febbraio, M., et al. 1999. A null mutation in murine CD36 reveals an important role in fatty acid and lipoprotein metabolism. J. Biol. Chem. 274:19055-19062. 